\title{
Free- and Open-Source Software for a Course on Network Management: Authoring and Enactment of Scripts Based on Collaborative Learning Strategies
}

\author{
Davinia Hernández-Leo, Miguel L. Bote-Lorenzo, Juan I. Asensio-Pérez, Eduardo Gómez-Sánchez, \\ Eloy D. Villasclaras-Fernández, Iván M. Jorrín-Abellán, Yannis A. Dimitriadis
}

\begin{abstract}
Manuscript received December 29, 2006. This work was supported in part by the e-Learning project EAC/61/03/GR009, Kaleidoscope NoE FP6-2002-IST-507838, Spanish Ministry of Education and Science projects TIC-2002-04258-C03-02 and TSI2005-08225-C07-04, and Autonomous Government of Castilla and León, Spain, projects VA009A05, UV46/04 and UV31/04. .

Davinia Hernández-Leo, Miguel L. Bote-Lorenzo, Juan I. Asensio-Pérez, Eduardo Gómez-Sánchez, Eloy D. Villasclaras-Fernández, Yannis A Dimitriadis are with the School of Telecommunication Engineering, University of Valladolid, Camino del Cementerio, s/n, 47011 Valladolid, SPAIN (phone: +34-983-423000; fax: +34-983423667; e-mail: \{davher@, migbot@, juaase@, edugom@, evilfer@ulises, yannis@\}tel.uva.es).

Iván M. Jorrín-Abellán is with the Faculty of Education, University of Valladolid, Paseo de Belén, 1, 47011 Valladolid, SPAIN (e-mail: ivanjo@pdg.uva.es).
\end{abstract}

Corresponding author: Davinia Hernández-Leo School of Telecommunication Engineering, University of Valladolid, Camino del Cementerio, s/n, 47011 Valladolid, SPAIN (phone: +34983-423000; fax: +34-983423667; e-mail: davher@tel.uva.es) 
Abstract-This paper describes a Computer-Supported Collaborative Learning (CSCL) case study in engineering education carried out within the context of a network management course. The case study shows that the use of two computing tools developed by the authors and based on Free- and Open-Source Software (FOSS) provide significant educational benefits over traditional engineering pedagogical approaches in terms of both concepts and engineering competencies acquisition. First, the Collage authoring tool guides and supports the course teacher in the process of authoring computer-interpretable representations (using the IMS Learning Design standard notation) of effective collaborative pedagogical designs. Besides, the Gridcole system supports the enactment of that design by guiding the students throughout the prescribed sequence of learning activities. The paper introduces the goals and context of the case study, elaborates on how Collage and Gridcole were employed, describes the applied evaluation methodology, and discusses the most significant findings derived from the case study.

Index Terms-FOSS, computer-supported collaborative learning (CSCL), IMS Learning Design, collaboration scripts, authoring tool, learning management system, case study. 


\section{INTRODUCTION}

Collaborative learning underlines the importance of interactions among members of groups of students to improve learning. Additionally, this educational approach has reportedly been successful in promoting the development of transversal competencies and skills very relevant for the professional future of engineering students [1]-[4]: working in groups, building arguments for discussion, explaining ideas to others, etc. Additionally, CSCL (Computer-Supported Collaborative Learning) is an interdisciplinary branch [5] of the Technology-Enhanced Learning (TEL) field that promotes the use of information and communications technologies for organizing, scaffolding, supporting, and evaluating such collaborative ways of learning. CSCL solutions also enable remote collaboration, thus opening new opportunities for distance (or blended) learning scenarios.

Nevertheless, collaboration among students does not always happen spontaneously. Moreover, not all types of collaboration are equally effective for achieving a particular set of learning objectives in all educational contexts [6]. Teachers can face this problem by providing students with guiding instructions indicating how they should collaborate concerning issues such as the groups to be formed by participants, the activities that should be performed by each group, the timing of each activity, etc. These sets of instructions constitute the collaboration scripts [6].

Creating and enacting effective collaboration scripts may be daunting tasks for teachers, even if they have previous experience in collaborative learning. Also, following a collaboration script may demand a significant additional effort for students, who must change the way they are accustomed to work [7]. These factors may hinder the adoption of collaborative learning by both educators and students who would thus not profit from the well-known benefits of this 
educational approach.

To tackle this problem, the authors developed two CSCL applications for facilitating the creation and enactment of collaboration scripts. The first application, Gridcole [8], is a script enactment system that automatically guides and coordinates the groups of students throughout the flow of learning activities defined in a collaboration script formalized using IMS Learning Design (IMS-LD) [9]. Gridcole can also provide students with all the computing tools and electronic documentation that, according to the script instructions, are needed to complete the learning activities. The second application, called Collage [10], is an authoring tool that helps teachers in the process of creating their own potentially effective IMS-LD collaboration scripts by reusing and customizing pattern-based templates according to the requirements of particular learning situations. These patterns formulate existing and proven effective pedagogical strategies, as similarly performed in other disciplines with their own well-known solutions [11]. Furthermore, Collage hides all the technical complexity associated to IMS-LD, which is an XML-derived notation not necessarily familiar to teachers.

Collage and Gridcole do not advocate the use of just one particular collaborative learning pedagogical strategy, defined a priori. On the contrary, they aim at enabling the teachers to select and adapt the most suitable pedagogical strategy, among those provided by Collage, and enact it (using the guidance and tool integration provided by Gridcole), for effectively achieving the desired learning objectives (both in terms of content and skills). The selection, adaptation, and enactment of the chosen collaborative pedagogical strategies is supported by Collage and Gridcole without requiring technical expertise and is not restricted to one particular type of learning context or discipline. Furthermore, as the technological support for the enactment of the learning situations is offered by third-party tools integrated by Gridcole, teachers do not suffer 
from the potential problems derived from the adoption of one particular set of learning tools that might eventually impose one particular pedagogical strategy [6].

Both Collage and Gridcole are developed based on existing and well-known FOSS tools for the creation and enactment of collaboration scripts. The FOSS nature of those existing tools has contributed to an important reduction in development efforts. Additionally, both Collage and Gridcole are also offered as FOSS to the CSCL community, thus enabling their modification and enhancement by third parties to support new pedagogical strategies (in the form of patterns) during the design of collaboration scripts and to integrate additional types of FOSS learning tools during their enacting. All the mentioned factors stress the importance of FOSS for the wide application and adoption of both Collage and Gridcole.

The main goal of this paper is to show that both Collage and Gridcole can be employed successfully in a real scenario of engineering education in which several collaborative learning strategies are applied. With this purpose, the authors complete a case study that aims at drawing conclusions related to several research issues concerning the impact of Collage and Gridcole on the authoring and enactment process in a real educational setting. In fact, the case study takes place in a real undergraduate network management course within telecommunication engineering studies. The authors believe that this type of case studies may illustrate the suitability of FOSSbased solutions, such as Collage and Gridcole, in promoting innovative learning scenarios within the engineering educational system.

The rest of the paper is organized as follows. Section II describes the educational context of the presented case study, highlights the role that FOSS plays in Collage and Gridcole, and illustrates their usage for authoring and enacting the pedagogical design of the case study. Section III focuses on the description of the methodology employed for evaluating the case study and for presenting and discussing the main findings. Finally, conclusions and future work can be found 
in Section IV.

\section{The Network MAnAgement CASE StUdy}

\section{A. Educational Context}

The case study reported in this paper takes place in an elective undergraduate network management course with 12 students. The experience is completed in the spring semester (March, 2006) of the fifth and last year of the telecommunications engineering curriculum at the University of Valladolid, Spain. The course contents include an overall view of the concepts and purpose of network management and a description of the main standard technologies in the field. The students have previously completed at least four 15-week-long courses on computer networks. Therefore, the assumption is that they know the main data transmission technologies and protocols employed in networks following the Internet standards. The whole course spans a 15-week-long semester and involves 30 lecture hours (one two-hour session per week) and 30 laboratory hours (also one two-hour session per week). The case study involves a single collaboration script defining face-to-face activities during two two-hour sessions (one week) devoted to the presentation of SNMP (Simple Network Management Protocol) Network Management standard [12]. Both sessions take place at the course laboratory, having 25 Intel Pentium IV-class machines running Linux 2.6.8. Additionally, this script also involves a distance learning activity during which students use their own personal computational resources (they did not have access to laboratory premises). For that activity the students just need an Internet connection and a Web browser. The script of the case study is the only one employed throughout the course. More details on the case study activities are provided in subsection II.C.

Unfortunately, the engineering studies to which the course belongs are characterized by a strong competitive environment in which collaboration and cooperation are wrongly perceived as 
equivalent. Assignments are divided into separate tasks that group members complete individually, without joint activities that induce socio-cognitive processes (characteristic of true collaborative learning [6]). Furthermore, the curriculum does not explicitly encourage the development of skills needed for the professional future of students. In the context of this study, the strategies that aim at promoting those skills are just adopted in a limited set of courses, under the personal teacher initiative. In fact, two previous courses in the curriculum, one working with computer networks [2] and another related to computer architecture [3], introduce collaborative pedagogical approaches with very limited technological support. The presented case study goes a step further by further exploiting the support of technology and, particularly, by using two FOSSbased CSCL tools (Collage and Gridcole) not specifically designed for this experience.

\section{B. CSCL approach based on FOSS}

As illustrated in Fig. 1, FOSS applications play a crucial role in the creation and enactment of the pedagogical design of the case study. Collage was developed as a collection of plug-ins of Reload, the first and current de facto reference implementation of a text-based IMD-LD editor [13]. Collage adds a new interface that includes graphical representations more suitable for non experts in IMS-LD and in the logic that enforces the process of creating collaboration scripts based on existing pedagogical approaches expressed as patterns (more details on Collage in section II.C). Gridcole is a collaboration-aware functional extension of the CopperCore ${ }^{1}$ IMS-LD reference engine [14]. Gridcole also adds the capability of integrating third-party tools to fulfill script requirements (described in section II.D). In the case study, Gridcole integrates three tools of very different technical natures: a Chat Tool developed by the authors using Grid-Services middleware provided by the Globus Toolkit FOSS [8]; the Quest Web-based questionnaire tool

\footnotetext{
${ }^{1}$ Reload and Coppercore are openly available as SourceForge.net projects.
} 
also developed by the authors [15], which uses the MySQL FOSS Data Base Management System; and the Synergeia Web-based shared document repository. Although Synergeia is not FOSS, the shared-document repository might be provided by other similar FOSS systems such as Moodle or dotLRN [4]. All Web-based tools used Apache Tomcat as the Web application container. Additionally all Web browsing was carried out by Mozilla Firefox [16]. All computers involved in the case study were running the Linux operating system.

\section{*** INSERT FIG. 1. ABOUT HERE ***}

Collage is FOSS in nature since this tool (as well as its documentation, examples, etc.) is freely available $^{2}$ to the CSCL community. Additionally, since IMS-LD is an open specification, its adoption fosters the development of interoperable FOSS design and enactment applications with similar or complementary functions of those of Collage and Gridcole. For example, dotLRN is a FOSS-based Learning Management System also capable of interpreting IMS-LD scripts and of customizing its own functionality according to script instructions. Consequently, dotLRN might play the role of Gridcole as a different IMS-LD script enactment system; however, dotLRN would not be able to integrate third-party CSCL tools.

The following two subsections provide a deeper insight into the usage of Collage and Gridcole within the particular educational and organizational context of the case study.

\section{Authoring the pedagogical design}

The main goals of the network management course include knowing the different versions of the SNMP protocol and becoming accustomed to scientific and technical literature in the field. Consequently, the educator decides that students should understand the contents of an important and well-known paper on network management [12], and be able to identify its most relevant

\footnotetext{
${ }^{2}$ http://gsic.tel.uva.es/collage
} 
ideas. A non-collaborative pedagogical approach might simply consist of providing the students with the paper, asking them to read it individually and elaborate on its content, and finally to write a list of the main ideas of the paper. Instead, in this case the teacher also wants students to develop competencies related to group work that they will need in their professional future and to improve the understanding of the paper contents. Therefore, she/he decides to create a collaborative pedagogical design, in the form of a computer-interpretable collaboration script, which takes into account both types of requirements (concepts and competencies).

Collage can assist the teacher in the creation of potentially effective collaboration scripts, using a design process based on patterns (CLFPs, Collaborative Learning Flow Patterns) that formulate collaborative learning strategies for structuring flows of activities. The first step of the design process is to select and combine, if required, some of the IMS-LD templates based on the CLFPs that Collage provides [10]. In addition to information about the patterns and examples of their application, Collage also presents the teachers with a list of "Attitudinal Objectives" (e.g., "Encourage sharing of ideas”, "Promote tolerance and respect”, etc.), "Procedural Objectives” (e.g., "Promote individual accountability”, “Focus students’ attention”, etc.), "Problem types” (e.g., "Divisible problem”, "Problem with many possible solutions”, etc.), and the "Complexity level” of the strategy enforced by the pattern (“Low-risk”, “Medium-risk”, and "High-risk”). Most of the objectives fostered by the CLFPs are collected in Blooms' taxonomy [17] (especially in the cognitive and affective domains). Moreover, CLFP objectives and proposals are in agreement with the meaningful learning approaches considered by Shuell [18] and other approaches, such as those in [19]. To be precise, CLFPs represent a way of providing scaffolding in contrast to regulation [20]. Scaffolding refers to the provision of a set of instructions that guides the collaboration in such a way that the probability of reaching successful learning increases. On the other hand, regulation is performed by monitoring the (free) collaboration so 
that the teacher intervenes when necessary to guide the collaboration in a more fruitful direction. By making the corresponding selections on the lists of educational objectives, problems, and complexity levels, the teacher provides Collage with requirements on learning goals and characteristics of the learning context and teacher experience (similarly proposed in [19], where learning processes are annotated by metadata related to learning purposes). With the provided information, Collage proposes the teacher a set of CLFPs that could eventually fulfill all the requirements and characteristics. Then the teacher decides which CLFPs will be used and how they can be combined to structure the flow of activities. The first column of Table I and the left frame of Fig. 2 show the result of this step, which is described next.

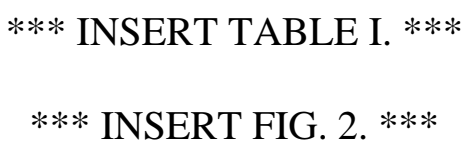

With the goal of fostering discussion and reaching agreement, the teacher selects the Pyramid CLFP, which promotes positive interdependence (i.e., students should develop the feeling that they need each other to succeed [7]). The number of levels of the Pyramid CLFP can be configured with Collage (Fig. 2). In each level of the pyramid, groups (from the previous level) join in larger groups to generate agreed "solutions". In this case the "solution" is a list of the most important ideas of the paper and the questions they would like to have answered. This list must be refined at each level of the Pyramid. Since the teacher is also interested in focusing students' attention on particular topics of the article, she/he plans a plenary discussion mediated by her/him and structured according to the TPS (Think-Pair-Share) CLFP for the last level of the pyramid.

Moreover, the teacher chooses to design the first pyramid level according to the strategy collected in the Jigsaw CLFP. The selection of this pattern is motivated so that the paper can be divided in different parts because the article includes several sections devoted to different 
versions of SNMP. An additional motivation for its use is that the Jigsaw strategy reduces students' work load but at the same time promotes a fare sharing of it (individual accountability) [7]. This pattern suggests that each participant in a (Jigsaw) group first studies a particular subproblem (a section of the paper). Then, the members of the different groups that have worked on the same sub-problem meet in an "experts group” to exchange ideas. Finally, each participant contributes with her/his expertise in the original group to tackle the global problem (i.e., the whole paper).

After selecting and combining CLFPs, the next step in the design process implies refining the resulting IMS-LD template to obtain a computer-interpretable script. This step includes particularizing the description of the learning activities (e.g., reading a part of the paper, discussing questions/ideas, etc.), providing information about roles and groups, establishing group-size limits, and determining and configuring the resources (tools and content) needed to support each activity. These tasks are accomplished using forms (Fig. 2), where the first activity of the second pyramid level is described. Table I summarizes the result of this refining step and details the planned time frame.

Of course, the described pedagogical design is just one instance of the possible alternatives that might have been adopted by the teacher in terms of CLFP selection and/or script refining. This joint usage of Collage and Gridcole allows the teacher to tailor the scaffolding and support of a collaborative learning setting, according to the targeted learning goals, by changing the CLFPs on which the script is based and by adding, modifying, and removing the activities of the script and the related learning objects. 


\section{Enacting the pedagogical design}

Gridcole is a learning management system that implements the "tailoring by soft integration" approach [8] and thus does not intend to provide by itself all the functionality that an educator may require in a collaboration script. By adopting this type of tailorability, the pedagogical strategy designed by the teacher is not restricted by the capabilities or limitations of the learning management system. Furthermore, Gridcole enables the use of the same tool in learning situations following different pedagogical strategies. Therefore, pedagogical strategies drive the use of tools and not the contrary. Gridcole tries to find that functionality in third-party tools, and to offer those tools in an integrated way to the participants in a collaborative learning situation. The tailoring of Gridcole to support a learning situation described in a given collaboration script can be easily made by educators by simply providing the system with a set of URLs to be associated with the tools defined in the script. Each URL may point to a Web-based tool or a grid service-based tool that may be either individual or collaborative. In the case study considered in this paper, Gridcole integrates two collaborative Web-based tools (Synergeia and Quest) and a collaborative grid service-based tool (a chat).

Of course, the technological support of the pedagogical strategies depends on the availability of learning tools that satisfy their requirements. In this sense, FOSS learning tools play an important role in the wide applicability of the Gridcole tailoring approach by reducing the investments on in establishing CSCL scenarios composed of a large number of tools and by enabling the modification of existing tools by third parties if eventually required by the pedagogical strategy.

Prior to the enactment of the script, the teacher must provide the system with the list of students who are allowed to join the scenario and the roles that they will play. The group formation is negotiated between the teacher and them. (The resulting groups are just active 
during the experience of the case study.) Learners can then join the system and start performing the learning activities specified in the script with the support provided by the system. In this sense, during the realization of the scenario, the system determines the collaborative or noncollaborative activities to be performed by participants while offering them the tools and documents that they can use in each activity. This performance is accomplished through the Web-based interface of the system that is shown in Fig. 3.

\section{*** INSERT FIG. 3. ***}

The top left frame of the interface indicates the sequence of activities that should be performed by the user. If the user clicks on the name of the activity, its description is shown in the right frame. Also, in the bottom left frame students can see the documents and tools available for the support of the activity. When the user selects a Web-based tool or a document, the resource is provided by the system using the right frame. If she/he decides to use a grid service-based tool, Gridcole automatically installs, configures, and launches a Java client in the user's machine so that the student can immediately start using the tool. In Fig. 3, for instance, students are involved in the "Expert phase of Jigsaw" (Table I). The student whose interface is shown in Fig. 3 is an “expert” on version 3 of SNMP, and thus the systems provide him with the document containing its description. Also, the student has selected the chat tool from the bottom left frame, and consequently, Gridcole automatically configures and launches the tool so that the student can talk to the other members of that particular group of "experts". The use of the chat tool is an example of how Gridcole integrates existing third-party tools in the learning situation. This integration supports the activities prescribed by the collaboration script according to the pedagogical strategy expressed by the selected CLFP. The pedagogical strategy (the jigsaw CLFP in the example) includes the creation of groups of "experts" in which collaboration among their members is 
expected to enhance the comprehension of one particular topic. Gridcole provides the chat tool to support those activities and therefore to contribute to the application of the pedagogical strategy.

\section{Evaluation OF THE CASE STUdY}

\section{A. Evaluation Methodology}

This section explains the method used to evaluate the case study. The case study involves an authentic learning situation, which includes many factors, such as contextual issues, characteristics of students and educators, the achievement of the educational benefits, and the impact of software systems. Therefore, a mixed evaluation method combining quantitative and qualitative data gathering techniques is applied [21]. Quantitative data are considered useful for showing trends. In addition, qualitative results are used to confirm or reject those trends, to understand them and to identify emergent features in the particular representative situation. The same mixed evaluation method was employed in previous case studies in which Collage and Gridcole were used separately [8], [10].

As mentioned in the Introduction, the main goal of the case study is to get evidence on whether a CSCL script created with Collage can be enacted, by means of Gridcole, in a real situation of engineering education. For achieving that goal, the evaluation of the case study narrows its focus to three important topics. The first topic considers the meaningfulness of the CSCL script created with Collage, i.e., whether the script created with Collage actually reflects the teacher's design intentions. This topic may show whether Collage (at least with the support of Gridcole in the case study) is capable of helping teachers to prepare learning situations in which their desired pedagogical strategies are put into practice. The second topic is related to the difficulties found by the students participating in the case study when interacting with the technological setting provided by Gridcole. This topic is intended to get further information on whether the way third- 
party tools are integrated by Gridcole raises unexpected usability problems. The third and last topic is related to the educational innovation, if any, that Collage and Gridcole represent with respect to previous students’ experience.

Table II shows the different data sources considered to evaluate the case study according to the mixed method ${ }^{3}$. Students' quantitative ratings and open explanations are collected in two Webbased questionnaires, which are answered before and after the experience. The teacher also completes a questionnaire once the experience is finished. That information is complemented by the use of observations gathered by an observer in the laboratory, log files generated by the software tools, student outcomes, and a focus group in which students are interviewed after the experience. With the goal of reaching valid conclusions, data are aggregated and analyzed comparatively, i.e., triangulated [22], using a qualitative analysis tool [23]. This tool facilitates the organized interpretation of the arguments regarding the different categories of study, which have been previously defined according to the issues of evaluation interest or which emerge during the analysis.

\section{*** INSERT TABLE II ***}

\section{B. Results and Discussion}

The Network Management case study described in this paper is designed to test the application of IMS-LD scripts created with the Collage authoring tool and enacted using the Gridcole system in engineering education. This research opportunity has been possible because of the use of existing FOSS (Fig. 1) and the development of new software reusing IMS-LD reference FOSS (Reload editor and Coppercore engine, see subsection II.A). Table III summarizes the findings and partial results after evaluation, some of which are discussed in more detail in this section.

\footnotetext{
${ }^{3}$ The support evaluation data are available at http://gsic.tel.uva.es/collage/nm_case_study
} 
*** INSERT TABLE III ***

Subsection II.C describes how the teacher creates the pedagogical design of the experience in the form of a computer-interpretable script using Collage. Considering the design process, she/he selects and combines the CLFPs that best serve the type of task to be solved and that best elicit the desired objectives related to collaborative learning. Then, the teacher particularizes the activities offered in the CLFPs, according to the requirements of the learning situation. Therefore, a global evaluation goal is to prove the meaningfulness of the created script, that is, whether the script created with Collage actually reflects the teacher's design intentions.

The first three findings of Table III confirm the fulfillment of this goal. A first quantitative indication in this sense appears in a closed question of [Quest-final] and [Quest-teacher]. All students (12 out of 12) and the teacher rate as positive (among the available possibilities: negative, acceptable, or positive) the structure of the experience regarding its utility to reach the objectives directly related to the content of the course. Besides, qualitative arguments confirm this result. In the [Quest-final] a student affirms “... the structure is very positive to understand the different SNMP alternatives. I have acquired a good knowledge of SNMP without a great effort." Others state "... it is positive to break down the paper so that we have collaborated to extract the fundamental concepts of SNMP. Moreover, we have worked with a technical article, what we had never done before."

The second finding verifies that the script structures the teaching / learning process by coordinating the flow of activities according to the combined CLFPs. A partial result underlying this conclusion (Table III) indicates that the guidance in the sequence of activities, as indicated by the script, was effective. Interestingly, the students did not find the script too coercive because they could collaborate freely within the activities. In fact, groups differ in the way they collaborate within activities as perceived comparing [Chat-expert-group-1], [Chat-expert-group- 
2], and [Chat-expert-group-3] (group-1 discussing doubts, group-2 identifying the main ideas, and group-3 commenting paragraph by paragraph). The observations recorded in [Observationsession-1] and [Observation-session-2] also clarify this result. In addition, one of the students states “... it is better if the coordination within activities is up to us, because each of us works her/his own way. For example we proceeded differently to Luis’ group ... [Focus].”

Furthermore, the third finding confirms that the script fosters the desired objectives related to collaborative learning. Students rate the collaboration with their classmates with an average of 5.17 (deviation of 0.37 ) (in a range of 1 (very negative) to 6 (very positive)). Also, the script truly promotes positive interdependence and individual accountability, which encourage students to reflect on the concepts and to practice the desired competencies. As one student mentions “... it demands an active participation and responsibility, because we have to explain our part to the other members of the group... [Focus].” The different data sources also show that the students reach discussion and agreement. For example, [Outcomes-jigsaw] and [Outcomes-2levelpyramid] show that all groups, in the different phases of the script, formulate the maximum number of ideas (10 or 8 depending on the phase) and (2) questions.

On the other hand, section II.D already illustrates how Gridcole enacts the script used in the case study, integrating the tools needed to support each activity. The evaluation results confirm that students follow the script successfully using the Gridcole system in the face-to-face and in the distance activities. The [Repository-log] shows that, after the first face-to-face session, 11 students read and posted comments (accessing through Gridcole) on the outcomes of the other members of the jigsaw group that they are joining in the next session. Moreover, not only do students find the system very useful supporting collaboration and indicating what to do and which tools to use in each activity, but they also consider that having access to the system from home provides flexibility. Some students affirm “... it is very helpful that the system indicates the 
objectives of each phase and provides direct access to the tools needed in each activity." In fact, they rate (in the range of 1 (not useful) to 6 (very useful)) with an average of 5.75 (deviation of 0.43) the usefulness of the system to accomplish the task step-by-step. In addition, a student states "I did not attend the first two-hour session and I managed to find out what the rest of the classmates did during this session from home. Otherwise, I would have been lost in the following session [Focus].”

The previous conclusion also points out the needs of flexibility that appear in this type of collaborative strategies. For example, in this case study the teacher skips the "Pair" phase of the TPS CLFP because of time restrictions [Observation-session-1], a step allowed by the script and the system. However, if three students (assigned to the same expert group) do not participate in the first session, changing the composition of the experts groups would have been necessary, so that at least two (out of four) students participate in the corresponding collaborative activity. Accomplishing such a step so with the current version of the system is not easy, but this concern is one of the major issues considered in the short-term future work. Other concerns include improving the intuitiveness of the interface and the addition of awareness and authentication utilities.

As a final finding, students highly appreciate the new learning scenario, as compared to their previous experience in terms of structuring collaboration and use of supporting technology. Significantly, when students are asked to compare how different this experience is as compared to their previous ones, nine answer that "they have found quite a lot of differences", and the other three indicate that "they have found a lot of differences". One of the main reasons supporting these opinions seems to be related to the provision of a collaboration strategy in contrast to the encouragement of totally free collaboration or plain cooperation. Some indications also emerge suggesting that the students suffer frustrating, non-scripted collaboration experiences and non- 
effective cooperation practices in their engineering education. A student regrets "I slightly prefer working individually, because in groups we have always divided the task in order to finish earlier and one of the members has often worked more than the rest... [Quest-initial].” Another student states “... for example, 'Name of a course' also promotes collaborative activities. However, the activities are a disaster because they are not well organized. In this experience, there is a structure, a plan and collaboration is really fostered. In contrast, in 'Name of the course' there is not any suggestion and nobody works, what does not lead to learning outcomes [Quest-final].” Besides, other students add “... sometimes the lack of efficiency makes us to waste time and hate working in groups. The realization of guided (or partly guided) activities and the use of new systems like Gridcole increase the efficiency and our interest in the activities [Quest-final].” Furthermore, students agree that this experience truly promotes the development of competencies useful for students” future professional life. Some students argue “... we, as engineering students, are rather individualist, but in our professional future we will work collaboratively. Thus, this has been a good training experience and there should be more like this along our education [Quest-final].”

All the presented findings support the evaluation topics described in section III.A. These findings provide further indications that confirm those of previous case studies in which they were used separately regarding the capabilities of Collage and Gridcole with respect to the easy design and enactment of technology-enhanced, collaborative learning situations that enforce effective pedagogical strategies selected and adapted by teachers. The strategy selected by the teacher of the case study, refined in the corresponding script, drove the use of all the involved third-party tools during the realization of the learning situation. Furthermore, the strategy succeeded in achieving the desired learning goals and the desired technological environment and was perceived as a positive innovation by the students. Finally, and not less important, during all 
the case study the teacher did not have to handle technological issues, a crucial aspect for the potential widespread adoption of CSCL situations such as those fostered by Collage and Gridcole.

\section{CONCLUSION}

This paper has presented an engineering education case study in which two CSCL tools (Collage and Gridcole) for authoring and enacting collaboration scripts based on pedagogical strategies have been evaluated using a mixed methodology.

The case study has shown significant evidence on the suitability of Collage and Gridcole for facilitating the introduction of collaborative learning within engineering studies, thus enabling the acquisition of competencies and skills particularly important for future professionals. Particularly, Collage was able to support the creation of a meaningful and effective script, and Gridcole could enact that script, integrating the tools needed to support face-to-face and distance activities, without significant usability or technical drawbacks. Finally, the students involved in the case study perceived the experience as an improvement over traditional, non-collaborative courses. All this evidence reinforces the results of previous case studies ([8], [10]) in which Collage and Gridcole were used separately. Those results underline the importance of collaborative pedagogical designs, based on existing pedagogical strategies and formalized with standard computer-interpretable notations, such as IMS-LD, which enables the use of enacting systems, such as Gridcole.

Additionally, FOSS has been a crucial factor in the development of Collage and Gridcole, both based on IMS-LD FOSS reference implementations, thus reducing drastically development efforts and offering a great flexibility to adapt them to specific educational needs. Also, Collage and Gridcole are offered as FOSS tools to the CSCL community. This fact is expected to 
contribute to their adoption by third-parties interested in enhancing and/or augmenting their capabilities, basically by adding support to new CLFPs in Collage and by integrating new types of learning tools (potentially FOSS-based) into Gridcole. Finally, the use of an open standard, such as IMS-LD, enables interoperability of Collage and Gridcole with other existing tools (authoring tools and learning management systems).

New case studies are needed to further evaluate the suitability of the presented approach in different educational, organizational, and technological contexts. For instance, the authors intend to use Collage and Gridcole for the design and enactment of a distance collaborative learning experience in March 2007. This new case study will involve doctoral students of three different Spanish schools of telecommunications and computer science engineering. Also, the authors are working in Collage improvements to support more pedagogical expressiveness and provide more pedagogical patterns to be selected by educators. Gridcole is also being enhanced with more security and awareness features and with the capability of integrating other types of CSCL tools.

\section{REFERENCES}

[1] D. Gillet, A. V. Nguyen-Ngoc, and Y. Rekik, "Collaborative web-based experimentation in flexible engineering education", IEEE Transactions on Education, vol. 48, no. 4, pp. 696-704, 2005.

[2] D. Hernández-Leo, J. I. Asensio-Pérez, and Y. Dimitriadis, "Collaborative learning strategies and scenario-based activities for understanding network protocols", Frontiers in Education 36th Annual Conference, San Diego, California, pp. S2F-19-24, 2006.

[3] A. Martínes, E. Gómez, Y. Dimitriadis, I. M. Jorrín, B. Rubia, and G. Vega, "Multiple Case Studies to Enhance Project-Based Learning in a Computer Architecture Course", IEEE Transactions on Education, vol. 48, no. 3, pp. 482-489, 2005.

[4] P. J. Muñoz-Merino, C. Delgado-Kloos, R. Seepold, and R. M. Crespo-García, "Rating the importance of different LMS functionalities", Frontiers in Education 36th Annual Conference, San Diego, California, pp. T1C-13-18, 2006.

[5] T. Koschmann, Paradigm shift and instructional technology. In: CSCL: Theory and Practice of an emerging paradigm, ed. T. Koshmann. New Jersey: Lawrence Erlbaum, 
pp. 1-23, 1996.

[6] P. Dillenbourg, Over-scripting CSCL: the risks of blending collaborative learning with instructional design. In: Three Worlds of CSCL. Can we support CSCL?, ed. P. A. Kirshner. Heerlen: Open Universiteit Nederland, pp. 61-91, 2002.

[7] D. W. Johnson and R. T. Johnson, Learning together and alone: cooperative, competitive, and individualistic learning, 5 ed., Allyn and Bacon, 1999.

[8] M. L. Bote-Lorenzo, E. Gómez-Sánchez, G. Vega-Gorgojo, Y. Dimitriadis, J. I. AsensioPérez, and I. M. Jorrín-Abellán, "Gridcole: a tailorable grid service based system that supports scripted collaborative learning", Computers \& Education, in press.

[9] R. Koper and B. Olivier, "Representing the Learning Design of Units of Learning", Educational Technology \& Society, vol. 7, no. 3, pp. 97-111, 2004.

[10] D. Hernández-Leo, E. D. Villasclaras-Fernández, I. M. Jorrín-Abellán, J. I. AsensioPérez, Y. Dimitriadis, I. Ruiz-Requies, and B. Rubia-Avi, "COLLAGE, a collaborative learning design editor based on patterns", Educational Technology and Society, vol. 9, no. 1, pp. 58-71, 2006.

[11] C. Alexander, S. Ishikawa, M. Silverstein, M. Jacobson, I. Fiksdahl-King, and S. Angel, A Pattern Language: Towns, Buildings, Construction, Oxford University Press, 1977.

[12] W. Stallings, "SNMP and SNMP v2: the infrastructure for network management", IEEE Communications Magazine, vol. 36, no. 3, pp. 37-43, 1998.

[13] C. D. Milligan, P. Beauvoir, and P. Sharples, "The Reload Learning Design tools", Journal of Interactive Media in Education, 2005.

[14] H. Martens and H. Vogten, A reference implementation of a Learning Design engine. In: Learning Design, a handbook on modelling and delivering networked education and training, eds. K. Rob and C. Tattersall. Heidelberg: Springer-Verlag, pp. 91-108, 2005.

[15] E. Gómez, B. Rubia, Y. Dimitriadis, and A. Martínez, "Quest, A Telematic Tool for Automatic Management of Student Questionnaires in Educational Research", 2nd European Conference on Technology, Information, Education Citizenship, Barcelona, Spain, 2002.

[16] A. Mockus, R. T. Fielding, and J. D. Herbsleb, Two case studies of open source software development: Apache and Mozilla. In: Perspectives on Free and Open Source Software, eds. J. Feller, B. Fitzgerald, S. A. Hissam, and K. R. Lakhani. Massachusetts: The MIT Press, pp. 163-209, 2005.

[17] B. S. Bloom and D. R. Krathwohl, Taxonomy of educational objectives, handbook I: Cognitive domain, Addison-Wesley, 1984.

[18] T. J. Shuell, Designing instructional computing systems for meaningful learning. In: 
Adaptive Learning Environments, eds. M. Jones and P. Winnie. New York: SpringerVerlag, pp. 19-54, 1992.

[19] M. D. Lytras, N. Pouloudi, and A. Poulymenakou, "Dynamic e-learning settings through advanced semantics. The value justification of a knowledge management oriented metadata schema", International Journal on E-Learning, vol. 1, no. 4, pp. 49-61, 2002.

[20] P. Dillenbourg, What do you mean by "Collaborative Learning"? In: Collaborative Learning. Cognitive and Computational Approaches, ed. P. Dillenbourg. Oxford, UK: Elsevier Science, pp. 1-19, 1999.

[21] A. Martínez, Y. Dimitriadis, B. Rubia, E. Gómez, and P. de la Fuente, "Combining Qualitative Evaluation and Social Network Analysis for the Study of Classroom Social Interactions", Computers and Educations, vol. 41, no. 4, pp. 353-368, 2003.

[22] R. E. Stake, The art of case study research, Sage Publications, 1995.

[23] Nud*IST, Software for Qualitative Data Analysis, Scolari, 1997.

Davinia Hernández-Leo received the M.S. degree in Telecommunications Engineering from University of Valladolid, Spain, in 2003.

She is currently an Assistant Professor at the Department of Signal Theory, Communications and Telematics Engineering, University of Valladolid. Her current research focuses on the technological support to the design of computer-supported collaborative learning scenarios.

Miguel L. Bote-Lorenzo received the M.S. and the Ph.D. degrees in Telecommunications Engineering from University of Valladolid, Spain, in 2001 and 2005, respectively.

He is currently an Assistant Professor at the Department of Signal Theory, Communications and Telematics Engineering, University of Valladolid. His research interests include CSCL systems and service oriented computing.

Juan I. Asensio-Perez received the M.S. and the Ph.D. degrees in Telecommunications Engineering from University of Valladolid, Spain, in 1995 and 2000, respectively.

He is currently an Associate Professor at the Department of Signal Theory, Communications and Telematics Engineering, University of Valladolid. His research interests include distributed FOSS-based systems and, particularly, distributed CSCL applications and integrated systems and network management.

Eduardo Gómez-Sánchez received the M.S. and the Ph.D. degrees in Telecommunications Engineering from University of Valladolid, Spain, in 1996 and 2001, respectively.

He is currently an Associate Professor at the Department of Signal Theory, Communications and Telematics Engineering, University of Valladolid. His research interests are distributed systems to support computer-supported collaborative learning (CSCL).

Eloy D. Villasclaras-Fernández received the M.S. degree in Telecommunications Engineering from University of Valladolid, Spain, in 2005.

He is currently a Research Assistant at the Department of Signal Theory, Communications and Telematics Engineering, University of Valladolid. His research focuses on the technological support to the design of the assessment embedded in computer-supported collaborative learning settings.

Iván M. Jorrín-Abellán received the M.S. and the Ph.D. degrees in Psychology and Pedagogy from University of Valladolid, Spain, in 2001 and 2006, respectively.

He is currently an Assistant Professor at the Faculty of Education, University of Valladolid. He is currently interested in the educational implications of computer-supported collaborative learning.

Yannis A. Dimitriadis (M’93) received the B.S. degree from the National Technical University of Athens, Greece, in 1981, the M.S. degree from the University of Virginia, Charlottesville, in 1983, and the Ph. D. degree from the University of Valladolid, Spain, in 1992, all in Telecommunications Engineering.

He is currently an Associate Professor at the University of Valladolid. His research interest include technological support to learning and work processes and machine learning.

Dr. Dimitriadis is a Member of the IEEE Computer Society and the Association for Computing Machinery. 


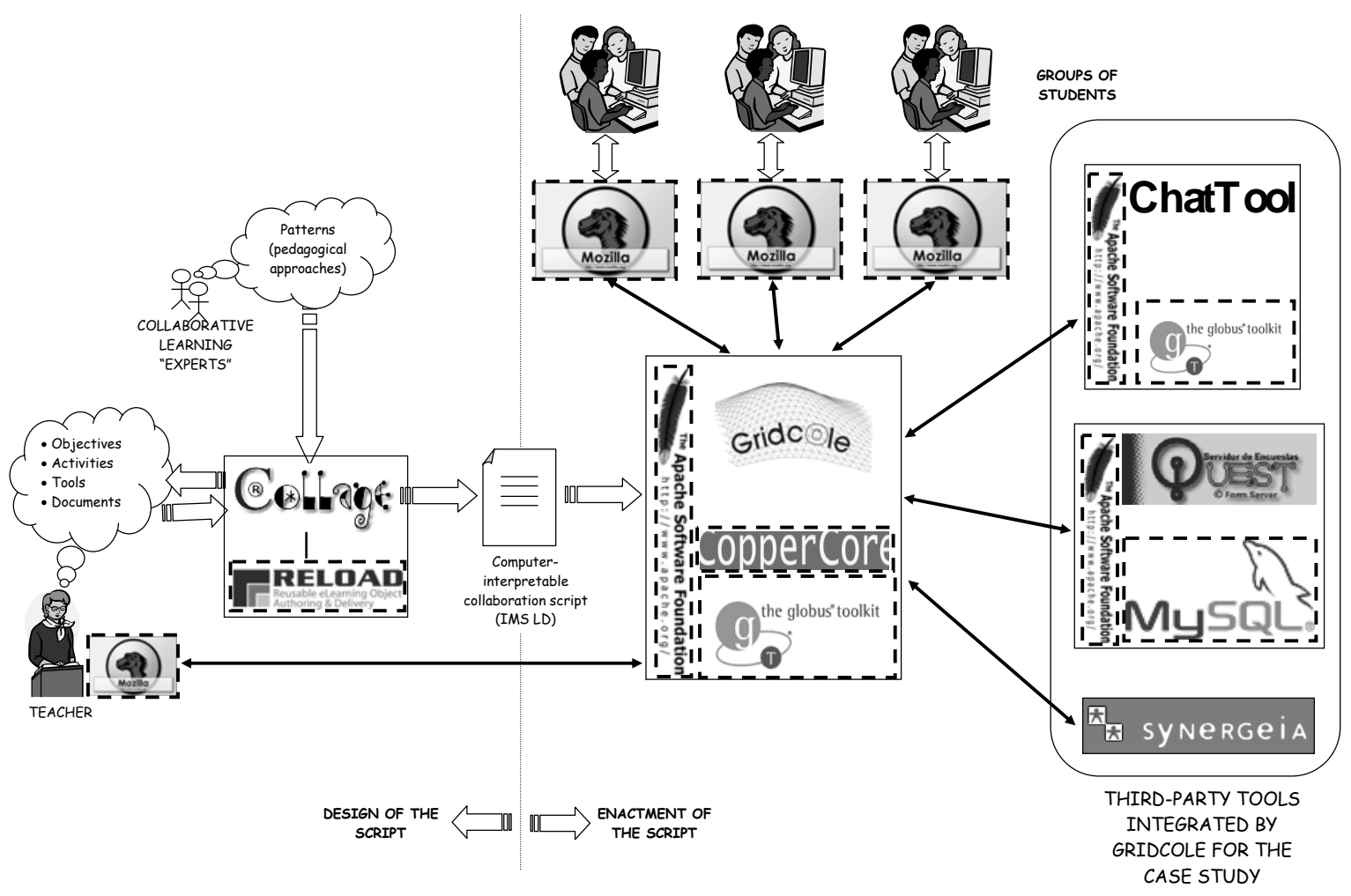

Fig. 1. Technological approach employed for the authoring and enactment of the pedagogical design of the case study. FOSS tools are indicated by means of dashed lines. 


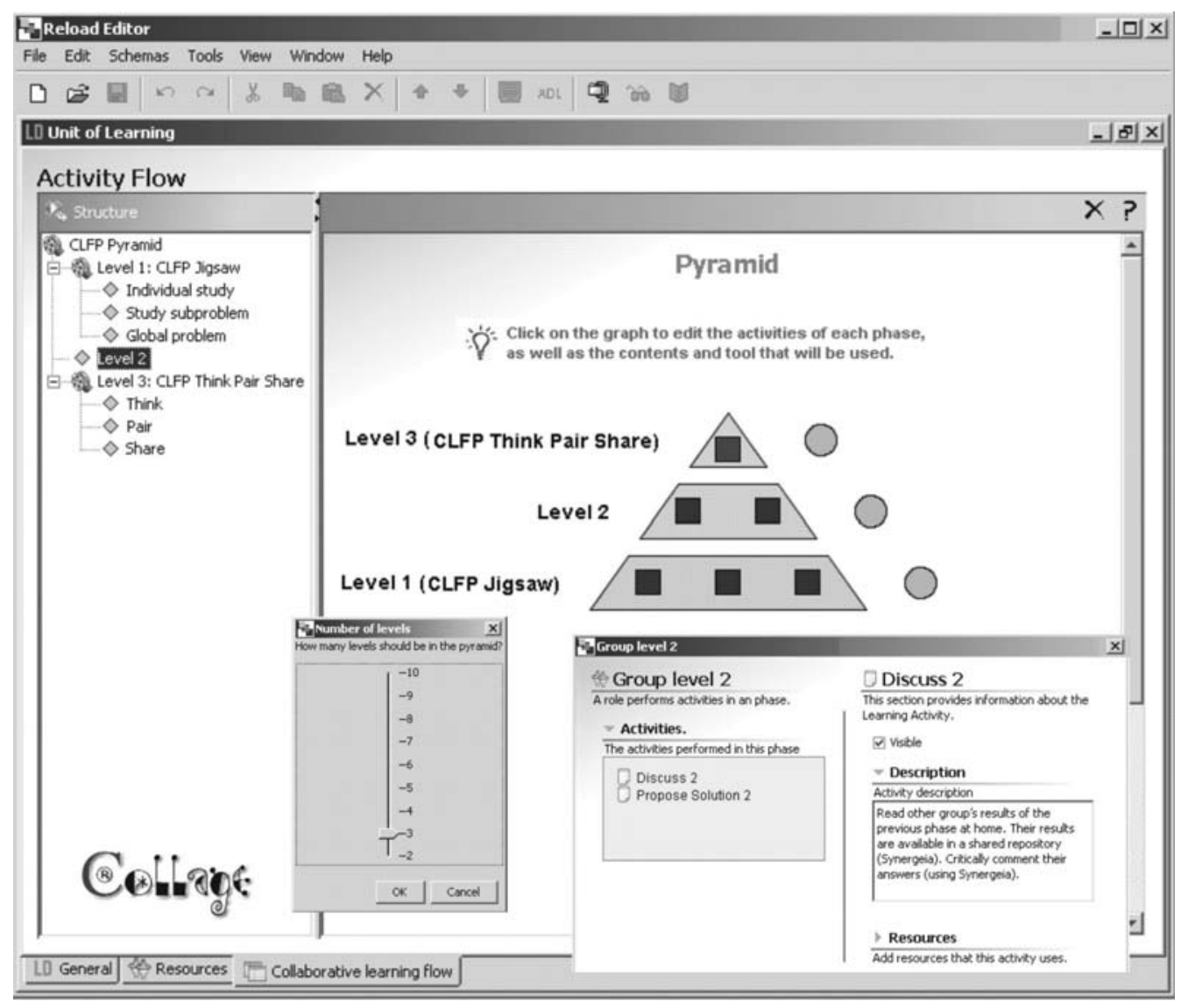

Fig. 2. Authoring the IMS-LD script reflecting the pedagogical design with Collage.

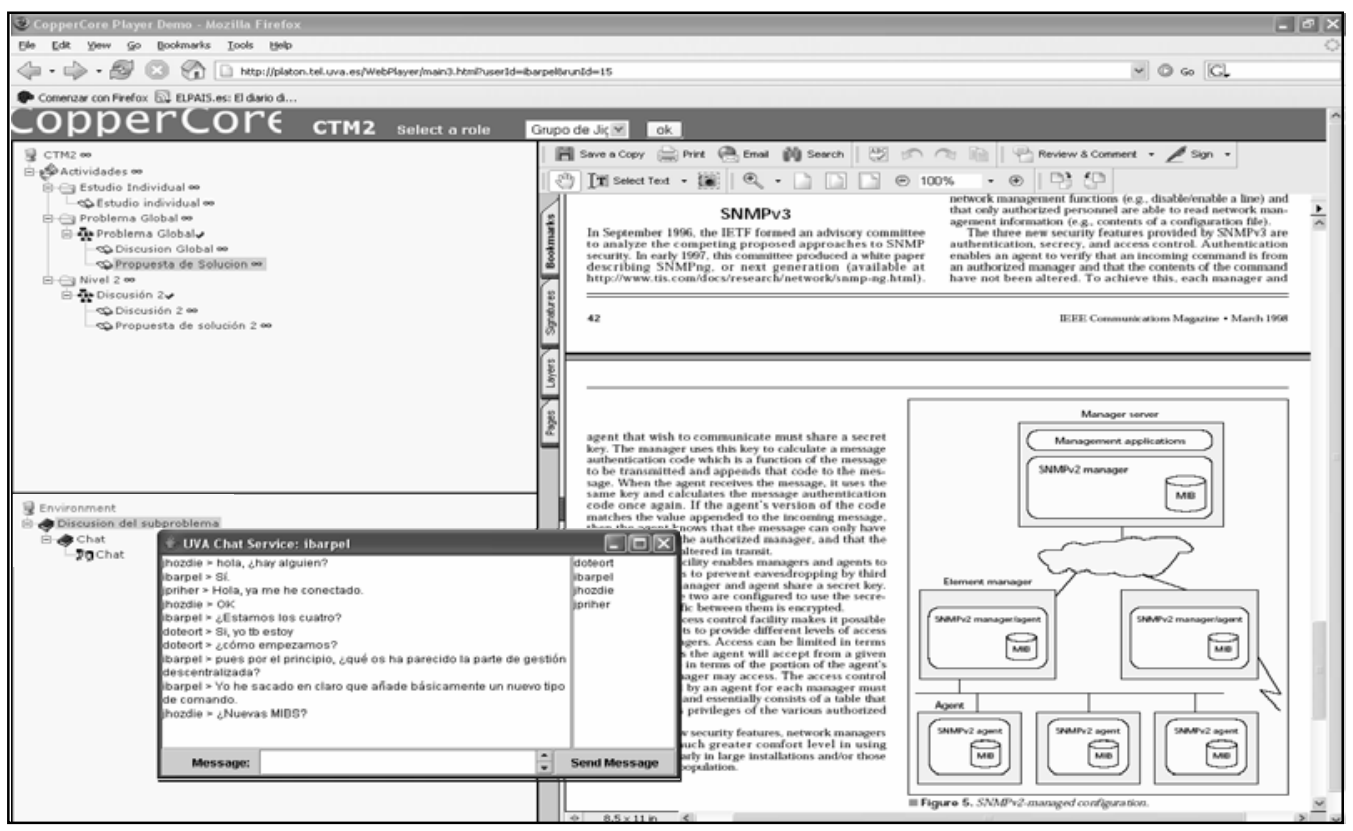

Fig. 3. Snapshot of Gridcole prototype along with the chat tool during the enactment of the pedagogical design. 
TABLE I

SuMmary OF THE PEDAgOgICAL BLENDEd DESIGN

\begin{tabular}{|c|c|c|c|c|}
\hline \multicolumn{2}{|c|}{$\begin{array}{l}\text { Learning } \\
\text { flow phase }\end{array}$} & $\begin{array}{c}\text { Group } \\
\text { characteristics }\end{array}$ & $\begin{array}{l}\text { Activity description and } \\
\text { supporting resources }\end{array}$ & $\begin{array}{l}\text { Time } \\
\text { frame }\end{array}$ \\
\hline \multirow{5}{*}{$\frac{\ddots 1}{2}$} & $\begin{array}{l}\text { Indivi- } \\
\text { dual } \\
\text { phase } \\
\text { of } \\
\text { Jigsaw }\end{array}$ & $\begin{array}{l}\text { Each "jigsaw } \\
\text { group” has at least } \\
3 \text { people. (Plan: } 4 \\
\text { groups of } 3 \\
\text { members.) }\end{array}$ & $\begin{array}{l}\text { - Read the introduction and one } \\
\text { of the three sections of the } \\
\text { paper available in Synergeia }\end{array}$ & \multirow{3}{*}{ 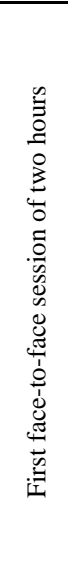 } \\
\hline & $\begin{array}{l}\text { Expert } \\
\text { phase } \\
\text { of } \\
\text { Jigsaw }\end{array}$ & $\begin{array}{l}\text { Each “expert } \\
\text { group” has at least } \\
\text { one member of } \\
\text { each “jigsaw } \\
\text { group”. }\end{array}$ & $\begin{array}{l}\text { - Discuss (using the chat) your } \\
\text { part of the paper with the } \\
\text { classmates that have read the } \\
\text { same part in order to } \\
\text { understand it well. }\end{array}$ & \\
\hline & $\begin{array}{l}\text { Jigsaw } \\
\text { phase } \\
\text { of } \\
\text { Jigsaw }\end{array}$ & $\begin{array}{l}\text { (See Pyramid } \\
\text { level 1: individual } \\
\text { phase of Jigsaw) }\end{array}$ & $\begin{array}{l}\text { - Explain to the rest of the } \\
\text { members of your "jigsaw } \\
\text { group" your part of the paper. } \\
\text { - The group has to agree on } \\
\text { which are the } 10 \text { main ideas of } \\
\text { the whole paper and } 2 \\
\text { questions. Use the tool for } \\
\text { questionnaires (Quest). }\end{array}$ & \\
\hline & $\frac{\sim}{\stackrel{D}{2}}$ & $\begin{array}{l}\text { Each group of the } \\
\text { second Pyramid } \\
\text { level comprises } \\
\text { from } 6 \text { to } 8 \\
\text { students. (Plan: } 2 \\
\text { groups in this }\end{array}$ & $\begin{array}{l}\text { - Read other group's results of } \\
\text { the previous phase at home. } \\
\text { Their results are available in a } \\
\text { shared repository (Synergeia). } \\
\text { Critically comment their } \\
\text { answers (using Synergeia). }\end{array}$ & \multirow[t]{2}{*}{ 壳 } \\
\hline & 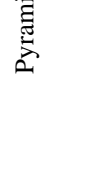 & $\begin{array}{l}\text { level of the } \\
\text { pyramid.) }\end{array}$ & $\begin{array}{l}\text { - Discuss face-to-face with } \\
\text { another “jigsaw group” and } \\
\text { jointly agree on the } 8 \text { main } \\
\text { ideas of the paper and } 2 \\
\text { questions (use Quest). }\end{array}$ & \\
\hline \multirow{3}{*}{ 总 } & $\begin{array}{l}\text { Think } \\
\text { phase } \\
\text { of TPS }\end{array}$ & $\begin{array}{l}\text { In this pyramid } \\
\text { level there is only } \\
\text { one group: the } \\
\text { whole class. }\end{array}$ & $\begin{array}{c}\text { Not visible } \\
\text { (there is no task in this phase) }\end{array}$ & \multirow{3}{*}{ 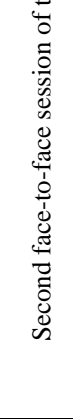 } \\
\hline & $\begin{array}{l}\text { Pair } \\
\text { phase } \\
\text { of TPS }\end{array}$ & $\begin{array}{l}\text { Each group of the } \\
\text { second level of } \\
\text { the pyramid is one } \\
\text { of the two } \\
\text { members of the } \\
\text { "Pair". }\end{array}$ & $\begin{array}{l}\text { - A spokes(wo)man of each } \\
\text { group exposes their conclusions } \\
\text { to the other group. }\end{array}$ & \\
\hline & $\begin{array}{l}\text { Share } \\
\text { phase } \\
\text { of TPS }\end{array}$ & $\begin{array}{l}\text { (See Pyramid } \\
\text { level 3: “think” } \\
\text { phase of TPS). }\end{array}$ & $\begin{array}{l}\text { - The teacher mediates a } \\
\text { discussion aiming at reaching } \\
\text { consensus. }\end{array}$ & \\
\hline
\end{tabular}


TABLE II

DATA SOURCES FOR THE EVALUATION OF THE CASE STUDY, AND LABELS USED IN THE TEXT TO QUOTE THEM

\begin{tabular}{|c|c|c|}
\hline Data source & Type of data & Labels \\
\hline $\begin{array}{l}\text { Web-based } \\
\text { questionnaires } \\
\text { before (initial) and } \\
\text { after the } \\
\text { experience (final) }\end{array}$ & $\begin{array}{l}\text { Quantitative ratings } \\
\text { and qualitative } \\
\text { explanations of the } \\
\text { students and the } \\
\text { teacher }\end{array}$ & $\begin{array}{l}\text { [Quest-initial] } \\
\text { [Quest-final] } \\
\text { [Quest-teacher] }\end{array}$ \\
\hline Observations & $\begin{array}{l}\text { Record of the } \\
\text { interactions and } \\
\text { incidents during the } \\
\text { experience }\end{array}$ & $\begin{array}{l}\text { [Observation-session-1] } \\
\text { [Observation-session-2] }\end{array}$ \\
\hline $\begin{array}{l}\text { Focus group } \\
\text { interviews after } \\
\text { the experience }\end{array}$ & $\begin{array}{l}\text { Qualitative students' } \\
\text { opinions }\end{array}$ & [Focus] \\
\hline Logs & $\begin{array}{l}\text { Document accesses } \\
\text { and recorded chat } \\
\text { conversations }\end{array}$ & $\begin{array}{l}\text { [Repository-log] } \\
\text { [Chat-expert-group-1] } \\
\text { [Chat-expert-group-2] } \\
\text { [Chat-expert-group-3] }\end{array}$ \\
\hline Student outcomes & $\begin{array}{l}\text { Documents } \\
\text { produced as a result } \\
\text { of activities }\end{array}$ & $\begin{array}{l}\text { [Outcomes-jigsaw] } \\
\text { [Outcomes-2level-pyramid] }\end{array}$ \\
\hline
\end{tabular}

TABLE III

MAIN CONCLUSIONS OFFERED BY THE RESEARCH CARRIED OUT ALONG THE CASE STUDY

\begin{tabular}{|c|c|c|}
\hline Findings & Partial results & Support data \\
\hline $\begin{array}{l}\text { The script authored with } \\
\text { Collage is contextualized } \\
\text { according to the engineering } \\
\text { education situation. }\end{array}$ & $\begin{array}{l}\text { - The structure of the experience is adequate for the type of task } \\
\text { and positive to reach the objectives of the course. } \\
\text { - The task is easy, though it motivates the students. }\end{array}$ & $\begin{array}{l}\text { Based on the analysis of } \\
\text { questionnaires and the } \\
\text { focus group interview. }\end{array}$ \\
\hline $\begin{array}{l}\text { The script guides the } \\
\text { teaching/learning process } \\
\text { coordinating the students at } \\
\text { the activity-level (according } \\
\text { to the CLFPs). }\end{array}$ & $\begin{array}{l}\text { - The experience proceeds as it is designed with Collage. } \\
\text { - The script assists the resources distribution. } \\
\text { - Students find to be effective the activity-level guidance } \\
\text { provided by the script. They do not find it too coercive because } \\
\text { they can collaborate freely within the activities. } \\
\text { - The selected tools support the realization of the activities, } \\
\text { though the use of the chat in the face-to-face activity is not } \\
\text { perceived as effective. } \\
\text { - Needs of further flexibility emerge. }\end{array}$ & $\begin{array}{l}\text { Supported by Synergeia } \\
\text { log files and the recorded } \\
\text { chat conversations as well } \\
\text { as on the observations and } \\
\text { questionnaires. }\end{array}$ \\
\hline $\begin{array}{l}\text { The script fosters the desired } \\
\text { objectives related to } \\
\text { collaborative learning. }\end{array}$ & $\begin{array}{l}\text { - The experience is successful in promoting collaboration. } \\
\text { - The experience fosters positive interdependence (students need } \\
\text { each other to succeed) and individual accountability (each } \\
\text { participant should be responsible for his/her contribution to the } \\
\text { group work). } \\
\text { - All the groups discuss and reach agreement. }\end{array}$ & $\begin{array}{l}\text { Questionnaires, } \\
\text { observations and student } \\
\text { outcomes support these } \\
\text { results. }\end{array}$ \\
\hline $\begin{array}{l}\text { Students follow the script } \\
\text { successfully using the } \\
\text { Gridcole system, which } \\
\text { interprets the script and } \\
\text { integrates the tools supporting } \\
\text { the activities. However, it can } \\
\text { be improved with awareness } \\
\text { and authentication utilities. }\end{array}$ & $\begin{array}{l}\text { - The Gridcole system is very useful supporting collaboration } \\
\text { and indicating what to do and which tools to employ in each } \\
\text { activity. } \\
\text { - Students successfully use Gridcole in the face-to-face as well } \\
\text { as in the distance activities. } \\
\text { - Having access to the system outside the lab provides } \\
\text { flexibility, though more flexibility is needed. } \\
\text { - The system could be improved with a more intuitive interface } \\
\text { and awareness and authentication functionalities. }\end{array}$ & $\begin{array}{l}\text { Based on the } \\
\text { questionnaires, log files, } \\
\text { observations and the } \\
\text { focus group interview. }\end{array}$ \\
\hline $\begin{array}{l}\text { Students highly appreciate the } \\
\text { learning scenario as compared } \\
\text { to their previous university } \\
\text { experience in terms of } \\
\text { structuring collaboration and } \\
\text { use of supporting technology. }\end{array}$ & $\begin{array}{l}\text { - The scenario introduces many differences with respect to } \\
\text { previous students' experiences. } \\
\text { - The script provides a collaboration strategy and does not } \\
\text { encourage totally free collaboration or mere cooperation, which } \\
\text { may not promote effective results. However, partially open } \\
\text { scripts might foster creativity and inquiry processes. } \\
\text { - The structure of the experience promotes active learning and } \\
\text { educational benefits useful for the professional future of the } \\
\text { students that are not truly considered in the educational system. } \\
\text { - Students appreciate the use of Gridcole. They have used the } \\
\text { tools before but not an integrating system. }\end{array}$ & $\begin{array}{l}\text { The initial and final } \\
\text { questionnaires answered } \\
\text { by students lead to these } \\
\text { conclusions. }\end{array}$ \\
\hline
\end{tabular}

